\title{
¿Sediment Resuspension and Transport from a Glider-Integrated Laser in Situ Scattering and Transmissometry (LISST) Particle Analyzer
}

\author{
Travis Miles, ${ }^{\mathrm{a}}$ Wayne Slade, ${ }^{\mathrm{b}}$ And Scott GlenN ${ }^{\mathrm{a}}$

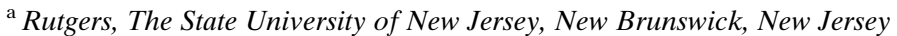 \\ ${ }^{\mathrm{b}}$ Sequoia Scientific, Inc., Bellevue, Washington
}

(Manuscript received 16 December 2020, in final form 28 April 2021)

\begin{abstract}
Suspended particle size and concentration are critical parameters that are necessary to understand water quality, sediment dynamics, carbon flux, and ecosystem dynamics, among other ocean processes. In this study we detail the integration of a Sequoia Scientific, Inc., Laser In Situ Scattering and Transmissometry (LISST) sensor into a Teledyne Webb Research Slocum autonomous underwater glider. These sensors are capable of measuring particle size, concentration, and beam attenuation by particles in size ranges from 1.00 to $500 \mu \mathrm{m}$ at a resolution of $1 \mathrm{~Hz}$. The combination of these two technologies provides the unique opportunity to measure particle characteristics persistently at specific locations or to survey regional domains from a single profiling sensor. In this study we present the sensor integration framework, detail quality assurance and control procedures, and provide a case study of storm-driven sediment resuspension and transport. Specifically, Rutgers glider RU28 was deployed with an integrated LISST-Glider for 18 days in September of 2017. During this period, it sampled the nearshore environment off coastal New Jersey, capturing full water column sediment resuspension during a coastal storm event. A novel method for in situ background corrections is demonstrated and used to mitigate long-term biofouling of the sensor windows. In addition, we present a method for removing schlieren-contaminated time periods utilizing coincident conductivity temperature and depth, fluorometer, and optical backscatter data. The combination of LISST sensors and autonomous platforms has the potential to revolutionize our ability to capture suspended particle characteristics throughout the world's oceans.
\end{abstract}

SIGNIFICANCE STATEMENT: This study details the integration and deployment of an optical particle size and concentration system on an autonomous underwater vehicle. The unique combination of this sensor and platform will enable broad sampling of suspended particle characteristics across the coastal and global oceans, within extreme storm events, in coastal river plumes, and throughout the deep oceans" "twilight zones." This will greatly enhance our ability to monitor water quality, sediment mobilization, ecosystem dynamics, pollutant fate and effects, and carbon export flux, among other important ocean-observing applications.

KEYWORDS: Extratropical cyclones; In situ oceanic observations; Instrumentation/sensors; Profilers, oceanic; Sampling

\section{Introduction}

In situ ocean observations of suspended particle size and concentration are important to monitor and study water quality, sediment dynamics, carbon export flux, fate and effects of pollutants, light propagation, ecosystem dynamics, water column visibility, and to ground truth remote sensing observations among other applications. Methods for measuring particle characteristics typically require labor intensive water sampling and sieving, or careful calibration of optical and acoustic backscatter sensors (Boss et al. 2018a; Agrawal and Pottsmith 2000; Bunt et al. 1999; Lynch et al. 1994; Thorne et al. 1991; Holdaway et al. 1999; Thorne et al. 2007). These approaches are not easily scalable beyond discrete sampling by ships or highly localized instrument deployment where calibration procedures remain valid. Laser In Situ Scattering and Transmissometry (LISST) particle analyzers have been used to

¿ Denotes content that is immediately available upon publication as open access.

Corresponding author: Travis Miles, tnmiles@marine.rutgers.edu reliably estimate particle size and concentration over the past two decades (Agrawal and Pottsmith 2000). These systems use laser diffraction as a composition insensitive method for sizing ensembles of particles in a sample volume. The near forward scattering of light onto concentric detector rings paired with inversion algorithms can be used to estimate particle size distributions (PSD) and volume concentration. Applications of LISST systems include storm-driven sediment resuspension (Dickey et al. 1998; Chang et al. 2001), sediment resuspension in estuaries and bays (Yuan et al. 2008; Wang et al. 2013), suspended sediment flocculates (Mikkelsen and Pejrup 2001), particle aggregation and disaggregation (Slade et al. 2011), phytoplankton size distributions (Karp-Boss et al. 2007), coastal water quality (Ahn et al. 2005), in flow-through systems across ocean basins (Boss et al. 2018b), bottom boundary layer studies (Agrawal and Traykovski 2001; Curran et al. 2007), monitoring the effect of dispersants during oil spill response (Bejarano et al. 2013), among many others. LISSTs along with other optical and acoustic sensors for monitoring suspended particles, are typically deployed on moorings, benthic landers, tripods, and other fixed point platforms (Trowbridge and Nowell 1994; Agrawal and Pottsmith 2000; Harris et al. 2003; Styles and Glenn 2005) or ship based profilers and underway 
systems for regional surveys. In this study we demonstrate the use of a newly integrated LISST-Glider into a Teledyne Webb Research Slocum autonomous underwater glider. Pairing of these technologies enables new possibilities for sustained sampling of particle size and concentration at regional scales and in conditions and locations not readily accessible by ship-based surveys.

In nearshore regions autonomous underwater gliders are the ideal platforms for collecting physical and biological data persistently across local and regional scales (from tens to hundreds of kilometers). Gliders have proven to be uniquely suited for collection of persistent profiles of optical data during the initiation, transport, and clearance of suspended sediment during hurricanes, coastal storms, and discharge events (Glenn et al. 2008; Miles et al. 2013, 2015; Bourrin et al. 2015). One of the first studies using gliders to investigate storm-driven sediment resuspension and transport detailed the impact of stratification on sediment dynamics (Glenn et al. 2008). Specifically, this study found that even during hurricane events, stratification inhibits full water column resuspension in summer months on the U.S. Mid-Atlantic Bight (MAB) continental shelf. This strong stratification is formed seasonally on the MAB, driven by rapid surface warming isolating the summer cold pool near bottom (Houghton et al. 1982). Storms in the fall season that break down stratification or occur after it has eroded can resuspend sediment throughout the full water column. Similar results for fall conditions were found in a follow-on study (Miles et al. 2013). In that study a fleet of simultaneously deployed gliders highlighted how local variability in bottom type can influence shelf-scale sediment resuspension and transport. Glider studies focused on storm-driven sediment resuspension and the influence of river runoff on particle assemblages have also been carried out in the Mediterranean Sea (Bourrin et al. 2015; Many et al. 2016). While these studies have used multiple wavelength optical backscatter measurements, these sensors alone have limited capability in determining particle size in situ.

In an initial effort to broadly determine in situ particle size from gliders, Miles et al. (2015) measured acoustic backscatter from a Nortek Aquadopp deployed alongside a Wetlabs optical backscatter sensor. Differing particle size sensitivity for acoustic and optical sensors allows for partitioning of "large" and "small" particle concentrations (Lynch et al. 1997). This approach was used to observe resuspension during Hurricane Sandy and qualitatively evaluate patterns of resuspension in an application of the Regional Ocean Modeling System (ROMS) coupled to the Community Sediment Transport Model (CSTM). Quantitative suspended particle concentration estimates from optical backscatter sensors require calibration with local sediment samples to measure accurate water column sediment concentrations (Bunt et al. 1999) and cannot identify particle size distributions. Over the course of a glider mission this type of calibration has limited feasibility, as the glider may be sampling over a broad spatial area (10-100 km) with highly variable sediment characteristics.

To fill this gap, we have recently integrated the newly developed Sequoia Scientific, Inc., LISST-200X into a Teledyne Webb Research (TWR) Slocum glider. This approach combines two proven technologies to enable broad, quantitative, sampling of particle size and concentration across a diversity of environments and conditions. In this paper we detail the sensor integration approach, in situ calibration and correction procedures, and an example of storm-driven sediment resuspension in the nearshore region of the MAB.

\section{Sensor integration and deployments}

\section{a. Sensor integration}

Slocum gliders are robotic uncrewed underwater systems with a demonstrated operational maturity over the last 20 years (Schofield et al. 2016). These low-power buoyancy-driven systems can carry out sustained missions of weeks to more than a year in water depths of $\sim 10-1000 \mathrm{~m}$, allowing them to sample nearshore, coastal, and deep ocean environments. Their broad sampling range includes extreme environments such as beneath hurricanes (Glenn et al. 2016; Miles et al. 2017) in coastal riverine environments (Schofield et al. 2015), and in polar oceans (Kohut et al. 2015). Slocum gliders profile the water column in a sawtooth pattern with speeds in the vertical direction of $10-15 \mathrm{~cm} \mathrm{~s}^{-1}$ and in the horizontal plane of 20 $25 \mathrm{~cm} \mathrm{~s}^{-1}$, resulting in high data density and full water column coverage. Gliders surface at preprogrammed intervals to obtain new GPS fixes, send data to shore, and receive new commands. Slocum gliders have modular payload bays located in the center section of the vehicle, which allow for customizable sensor loadouts and a flexible system for integrating new sensors.

Sequoia Scientific developed a LISST particle sizing instrument to fit within a Slocum second- (G2) and thirdgeneration (G3) glider. The optical arrangement of the LISST-Glider is based on the Sequoia Scientific LISST200X but mounted to fit within a Slocum glider hull section (Fig. 1). This system uses a "monoblock" optical head with the end cap machined as a solid component incorporating both receive and transmit windows for increased robustness of alignment under variations in temperature, pressure, and possible impacts. The basic measurement system is a sample volume exposed to ambient flow, flanked by a windowed pressure housing containing the laser source, and collimation optics, and the receive optics and detector array. The transmit optics consists of a fiber coupled 660-nm laser diode source with a beam splitter and reference photodetector and a lens providing a collimated source beam into the sample volume. The receive optics contains a focusing lens and a 36-element photodetector array placed at the focal plane of the lens. By the Fourier transform property of this lens, light scattered at a given angle at any point along the sample volume will be incident onto the ring detector plane at the same distance from the optical axis. A pinhole at the focal point allows transmitted light to be passed to a photodetector for measuring beam transmission. The LISST system is designed to measure the size distribution of particles from 1.00 to $500 \mu \mathrm{m}$ in 36 size classes at $1 \mathrm{~Hz}$ (Agrawal and Pottsmith 2000; Agrawal et al. 2008).

The LISST-Glider was integrated into a Slocum glider short hull section, commonly referred to as a stack-on bay (Fig. 1). This configuration allows for the LISST to be rapidly installed or removed from an available glider with limited impact on other sensor loadouts. A tie-rod extension and wiring harness 

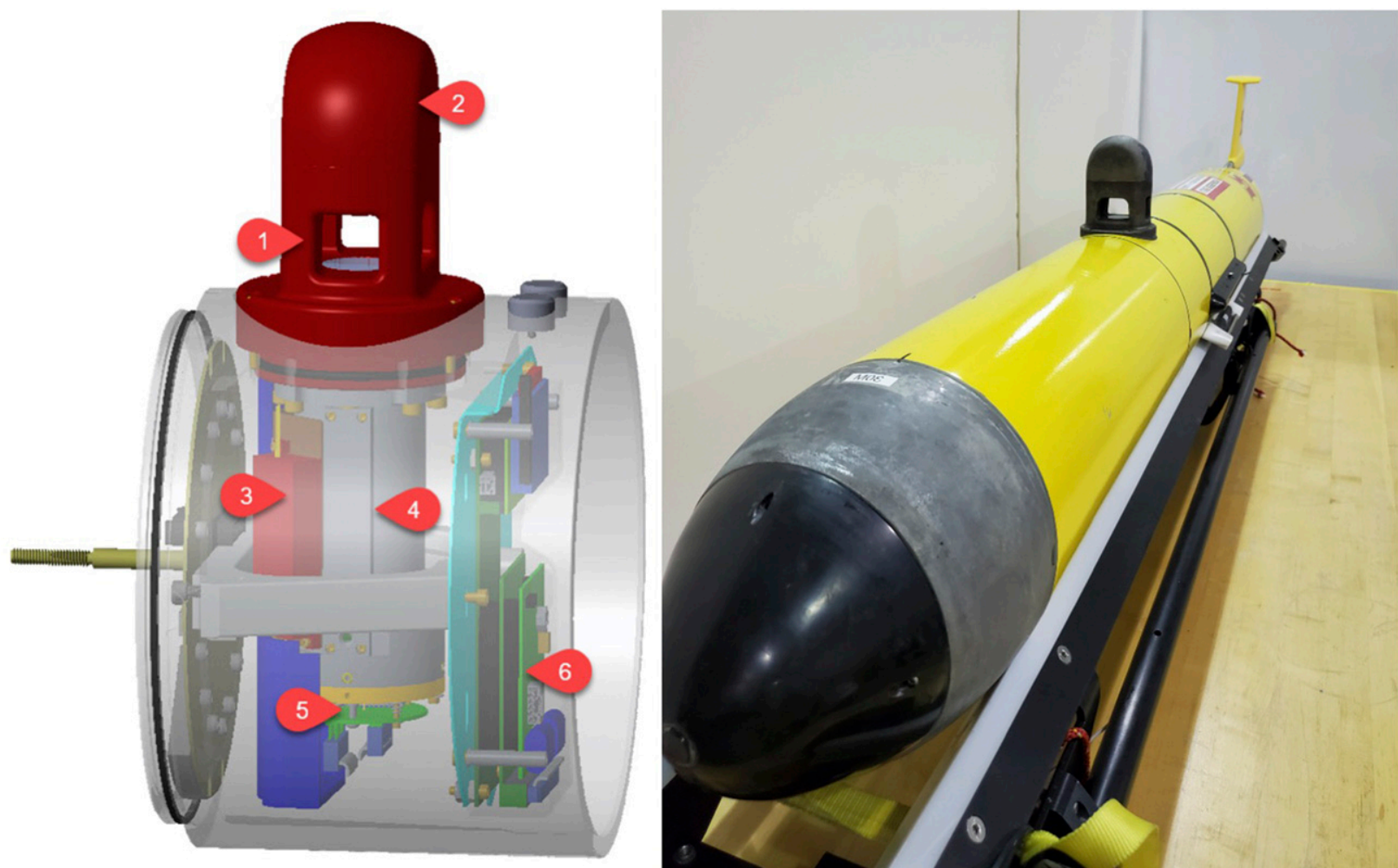

FIG. 1. (left) A schematic view of the LISST-Glider shows that the sample volume (label 1) is a 2.5-cm-pathlength scattering volume flanked with fused quartz windows for durability. The beam collimation optics and reference detector are also contained in the optical head (label 2), connected to a fiber coupled diode laser module (label 3). Scattered light is received through the lens tube (label 4), which also contains an extended detector array. The primary ring detectors and transmission sensor (label 5) are mounted on an XY stage that is used to adjust the instrument alignment, which can then be locked into place. An electronics section (label 6) digitizes the analog signals from the scattering detectors, controls the sampling process, logs the full scattering dataset, and calculates beam attenuation particle size metrics (i.e., mean size and total concentration). (right) A view of the LISST-Glider integrated into a G2 Slocum glider.

enable connection directly fore of the standard payload bay. During LISST-Glider production, quality control tests used bead standards to verify alignment and centration of the detector array. Factory clean water background measurements are stored on the instrument for use in data processing. These can be replaced by user-collected background measurements for both real-time onboard processing and with recovered datasets postdeployment following standard LISST-200X procedures. The resulting LISST-Glider payload bay underwent extensive pressure and thermal cycling at TWR. Currently, commercially available systems are rated to $600 \mathrm{~m}$. Default sampling settings, and those used in this study, include 32 measurements averaged every second with full datasets saved on board.

New firmware was developed that allows the LISST-Glider to be controlled by the glider science controller. Raw laser scattering data are stored on board the instrument in binary files compatible with standard LISST-200X processing software. These raw files contain all ancillary data needed to process the raw scattering measurements to particle size distribution. In the default glider configuration, the LISST-Glider generates a separate binary file for each glider segment, the data collection period between each subsequent glider surfacing. As for the standard LISST-200X, the firmware also calculates beam attenuation from transmission measurements and estimates of particle volume concentration and Sauter mean diameter in real time (Agrawal and Mikkelsen 2009); these parameters are output to the glider and available for transfer to shore as standard real-time glider output variables in glider binary files. Stored full-resolution data can be downloaded upon glider recovery and processed using Sequoia Scientific software as in standalone LISST applications. Additionally, Sequoia Scientific provides Mathworks, Inc., MATLAB functions, which were used in this study to merge LISST recovered data with full-resolution Slocum glider data using Slocum Power Tools (https://github.com/kerfoot/spt/wiki).

\section{b. Glider configuration}

The LISST-Glider science bay used in this study was integrated into a TWR Slocum G2 glider, RU28. This glider was operated by the Rutgers University Center for Ocean Observing Leadership (RUCOOL) on behalf of the State of New Jersey Department of Environmental Protection (SNJ-DEP). These SNJ-DEP deployments are typically focused on mapping nearshore water quality, specifically nearshore hypoxic conditions that may impact critical fisheries and recreation in 


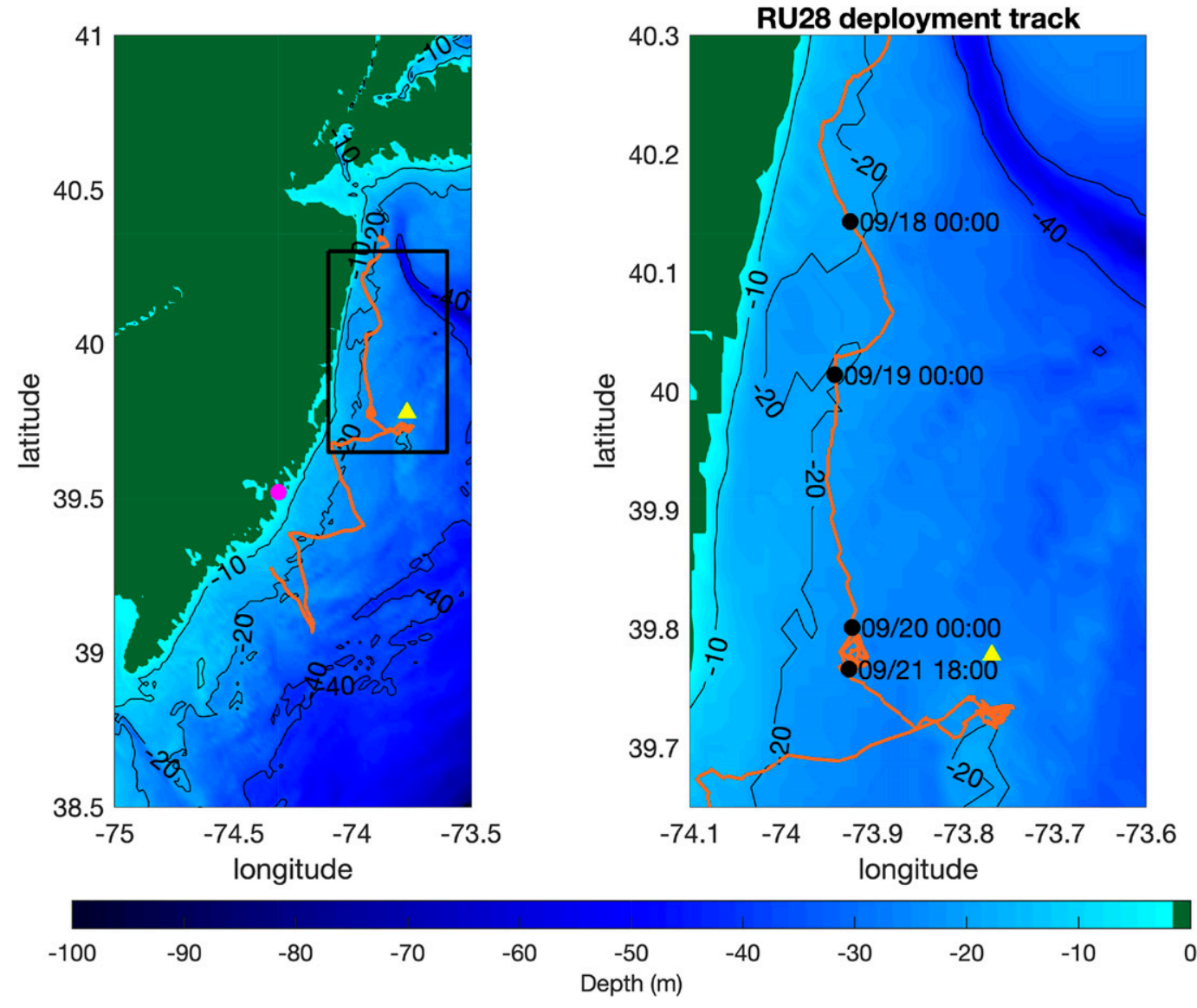

FIG. 2. (left) RU28's full deployment track in orange with the Rutgers University Marine Field Station Met Tower (magenta circle) and Buoy 44091 (yellow triangle); the black-outlined box represents (right) the zoomed area where the glider was located during the storm period.

New Jersey. These deployments target the autumn transition period (September-November) in late summer and early autumn. During this time, summer stratification leads to low oxygen in the bottom cold pool, a seasonal subsurface feature characterized by cold temperatures $\left(<10^{\circ} \mathrm{C}\right)$ isolated from the atmosphere (Houghton et al. 1982). Extratropical cyclones, colloquially referred to as "nor'easters" or fall transition storms, pass through the region and incrementally erode stratification (Lentz 2017), redistribute oxygen and nutrients, and mobilize and transport sediment (Glenn et al. 2008).

Glider RU28 was a shallow water glider with a 30-m pump designed for rapid inflection at the surface and bottom. This gearing for shallow water allows it to maintain greater speeds at inflections and to more quickly return to a nominal flight speed. RU28 was equipped with a suite of sensors in addition to the LISST-Glider system. This included a Sea-Bird Scientific Co. pumped conductivity-temperature-depth (GPCTD) sensor; a Sea-Bird ECO Triplet that measured chlorophyll fluorescence, optical backscatter at $700 \mathrm{~nm}$ (bb700), and colored dissolved organic matter (CDOM); and an Aandera Data Instruments AS oxygen optode that measures oxygen concentration and saturation. These sensors are maintained and calibrated following an Environmental Protection Agency
Quality Assurance Project Plan (QAPP) (Kohut et al. 2014) and following protocols detailed in the Mid-Atlantic Regional Association Coastal Ocean Observing System (MARACOOS) Regional Information Coordination Entities (RICE) certification (https://maracoos.org/certification.shtml). This includes factory calibrations of the GPCTD and optode following manufacturer recommendations (calibration every 1-2 years), predeployment comparisons with laboratory-based instruments and measurements, and comparisons with calibrated instruments in situ at deployment and recovery.

\section{c. Glider deployment}

Slocum glider RU28 was deployed on 15 September 2017 and recovered on 3 October 2017, near Sandy Hook and Atlantic City, New Jersey, respectively (Fig. 2a). The glider carried out a nearshore survey with onshore and offshore zigzags near the 20-m isobath as it transited southward along the New Jersey coast. RU28 was programmed to surface at $\sim 2$-h intervals to obtain new waypoints, telemeter real-time data, and calculate dead-reckoned current velocities at sufficient resolution to resolve tidal variability. This resulted in 201 segments over 18 days with a mean of 60 profiles collected per $\sim 2$-h segment. The glider was piloted to collect data while 

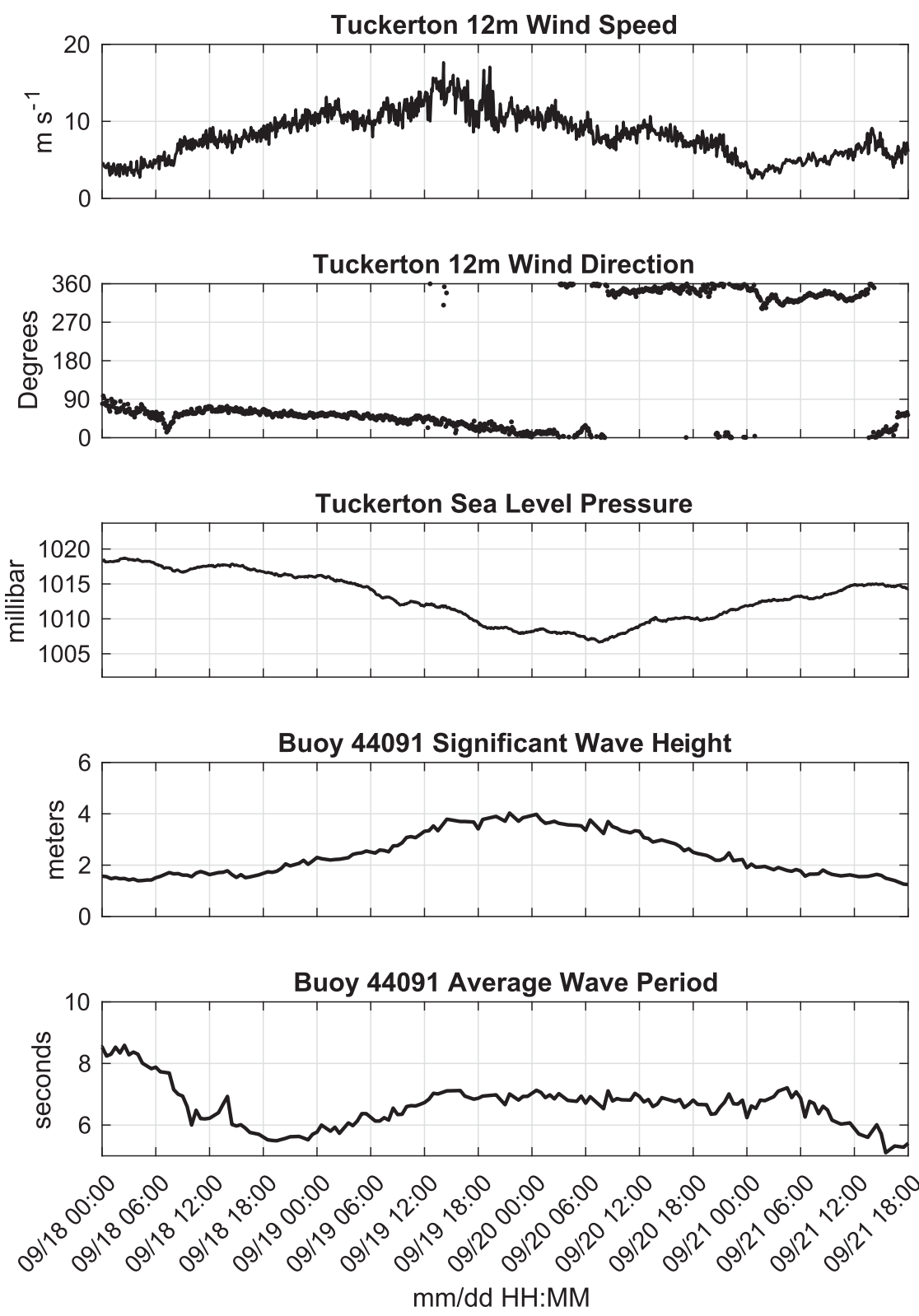

FIG. 3. The RUMFS Tuckerton Met Tower (top) wind speed, (top middle) wind direction from, and (middle) sea level pressure, and Buoy 44091 (bottom middle) significant wave height and (bottom) average wave period.

transiting for the majority of the deployment. However, a coastal storm event passed through the region on 18-22 September (Fig. 3). By 0000 UTC 20 September RU28 was programmed to hold position just offshore of the $20-\mathrm{m}$ isobath at $39.78^{\circ} \mathrm{N}$ and $73.92^{\circ} \mathrm{W}$ (Fig. 2b) east of Barnegat Bay, New Jersey. This stationkeeping location was approximately $45 \mathrm{~km}$ to the northeast of the Rutgers University Marine Field Station (RUMFS) Met Tower and $13 \mathrm{~km}$ west of National Data Buoy Center (NDBC) Buoy 44091. For the majority of this time period, the glider maintained a small watch circle $(<2.5 \mathrm{~km})$. Our analysis of the LISST-Glider output focuses on the short period from 0000 UTC 18 through 1800 UTC 21 September. This time period includes large vertical density gradients while the glider was in transit, and strong storm forcing during unstratified conditions while the glider was station keeping (Fig. 4).

\section{d. Deployment site sediment characteristics}

The sediment characteristics and resuspension processes throughout the region that RU28 sampled during the storm event has been extensively studied (Keen and Glenn 1995; Traykovski et al. 1999; Styles and Glenn 2002; Gargett et al. 2004; Styles and Glenn 2005; Glenn et al. 2008; Goff et al. 2008; Miles et al. 2013, 2015). These additionally include some of the earliest studies with the LISST (Agrawal and Pottsmith 2000; Agrawal 2005) 

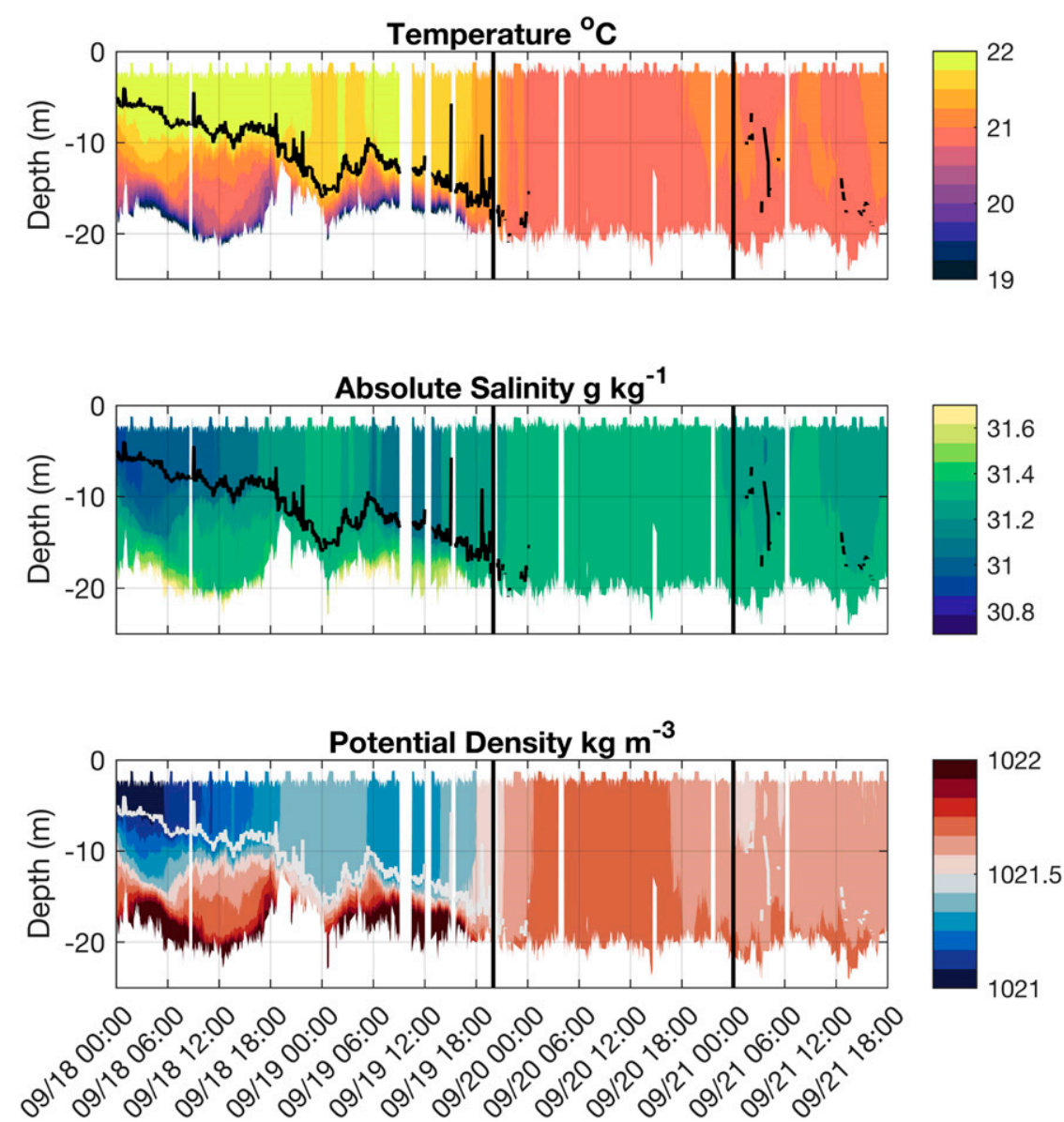

FIG. 4. Glider cross sections of (top) temperature, (middle) absolute salinity, and (bottom) potential density. Contour lines (black in the top and middle panels and gray in the bottom panel) represent the surface mixed layer depth. Vertical black lines represent the primary resuspension event time period.

deployed at the Long-term Ecosystem Observatory (LEO-15) site. These and other studies have characterized the New Jersey inner shelf as a region with a typically sandy bottom with median particle diameters of near $400 \mu \mathrm{m}$; however, significant patchiness exists (Goff et al. 2008; Miles et al. 2013) with typically larger grain sizes on the inner shelf to the north, and smaller to the south. For estimates of sediment transport in this study we assume particles during the main storm event are noncohesive sands with a density of $2650 \mathrm{~kg} \mathrm{~m}^{-3}$ when converting from volume concentration to mass concentration, ideally future LISST-Glider deployments should include in situ sampling of sediment type at deployment and recovery at a minimum, coincident with water column calibration information.

\section{e. Meteorological and wave data}

Wave data are from NDBC Buoy $44091\left(39.78^{\circ} \mathrm{N}\right.$ and $73.77^{\circ} \mathrm{W}$ ), a Coastal Data Information Program (CDIP) buoy owned and operated by the U.S. Army Corp of Engineers with data provided by Scripps Institute of Oceanography. This system is a Datawell directional buoy (Mark 3) that collects wave energy, wave direction, and sea surface temperature. Significant wave height, wave period, and bottom orbital velocities were estimated following linear wave theory using measured spectra (Wiberg and Sherwood 2008), with bottom orbital velocities estimated at 20-m depth, the approximate water column depth during RU28's station-keeping time period.

Additionally, we use wind data from the RUCOOL-operated 12-m meteorological tower located near the RUMFS in Tuckerton, New Jersey. The tower is equipped with a suite of atmospheric sensors including an R. M. Young Co. sonic anemometer model 81000 mounted at $12 \mathrm{~m}$ above ground level. The sonic anemometer collects wind speed at $0.01 \mathrm{~m} \mathrm{~s}^{-1}$ resolution with an accuracy of $0.05 \mathrm{~m}^{-1}$ within the $0-30 \mathrm{~m} \mathrm{~s}^{-1}$ range. Wind direction measurements have a $0.1^{\circ}$ resolution with a $2^{\circ}$ accuracy at speeds of $1-30 \mathrm{~m} \mathrm{~s}^{-1}$.

\section{LISST-Glider postprocessing}

\section{a. Background correction}

Typical ship-based LISST operations include clean water background measurements either before each profile, daily, or 

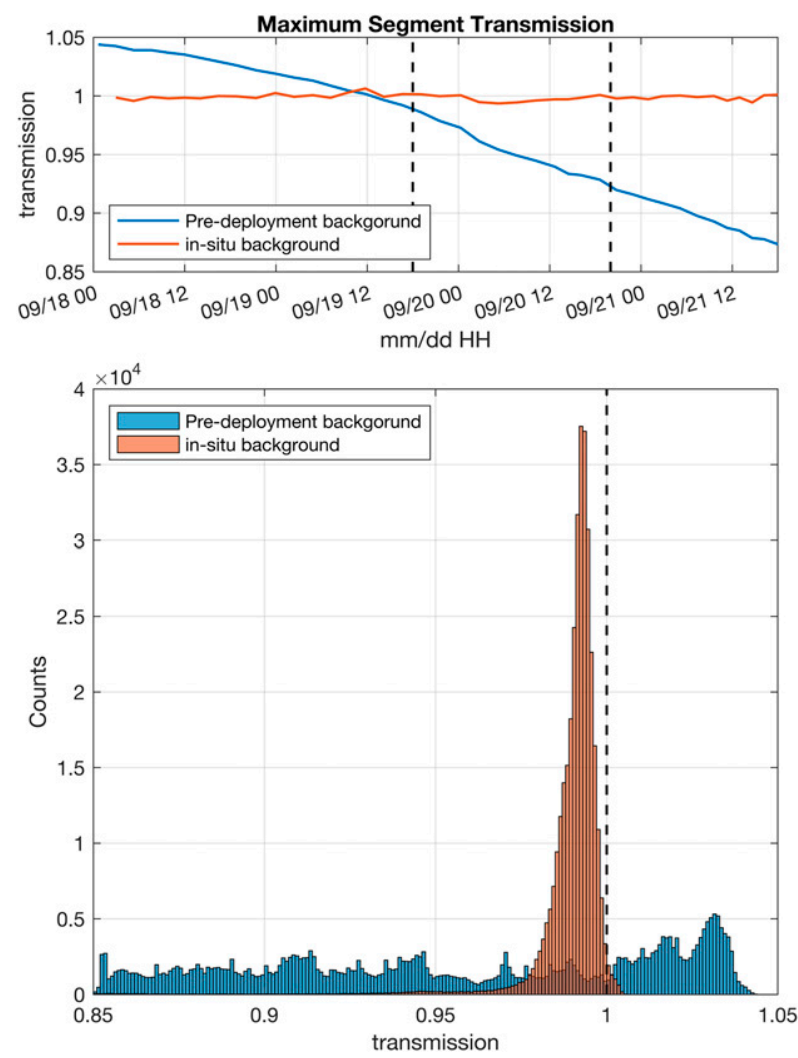

FIG. 5. (top) A comparison of the maximum transmission per $\sim 2$-h glider segment using only the predeployment background correction (blue) and the in situ correction method (red). The vertical black lines indicate the storm sediment resuspension time period. (bottom) Histograms of all transmission measurements using only the predeployment background correction (blue) and the in situ correction method (red). The vertical black line shows a value of 1 for reference.

as needed depending on environmental conditions. While this approach is not possible for an autonomously deployed vehicle, we demonstrate a method for carrying out in situ background corrections to account for biofouling and other mechanisms of sensor drift. LISST-Glider background measurements were taken in the laboratory predeployment on 13 September. The instrument windows were cleaned with lens paper and isopropyl alcohol, taking care not to scratch windows. The sample volume was covered with black tape to create a watertight dark chamber. In this case we used degassed deionized water for background measurements, although if it is available, for highest accuracy Sequoia Scientific recommends using filtered seawater from the study site, allowed to degas overnight if needed (Boss et al. 2018b; Agrawal and Pottsmith 2000). Sensor windows were visually inspected to ensure that no bubbles were present. Standard LISST background correction procedures were carried out according to the LISST-200X user's manual (https://www.sequoiasci.com). Three consecutive passing background measurements were taken before being saved to the instrument. Maximum transmission values using only the predeployment calibration from each segment are shown in Fig. 5 in blue. The resulting maximum transmission values show progressively decreasing transmission as well as initial transmission values greater than 1 . The transmission values greater than 1 suggest poor laboratory calibration relative to in situ water clarity despite the methods noted above. The progressive decrease in transmission indicates some combination of fouling and sensor drift over time. Linear biofouling over time scales of a few weeks is not unexpected; see, for example, Manov et al. (2004). In their deployments with open sensors such as transmissometers and fluorometers without antifouling treatment, data showed level-1-3 biofouling over $\sim 3$ weeks, with stationary sensors.

To mitigate the progressive decrease in transmission, in postprocessing we utilize in situ data to carry out dynamic background corrections similar to those utilized by Barone et al. (2015). Specifically, for each glider segment we find the time point with the maximum transmission within each $\sim 20$-h period. If coincident bb700 measurements from the ECO Triplet were $<0.005 \mathrm{~m}^{-1}$ the raw data were extracted and used as a background for that particular segment. Segments with coincident bb700 values $>0.005 \mathrm{~m}^{-1}$ were contained to the main storm sediment resuspension period between 1800 UTC 19 and 2000 UTC 20 September. During this storm-sampling period, we interpolate background information linearly from the last segment before the resuspension event to the first clear segment following resuspension. The resulting values of maximum transmission are shown as a red line in (Fig. 5a), with the full distributions shown in the Fig. 5b. The maximum transmissions now plot at a horizontal line near one, and the full distribution of the in situ corrected data falls mostly between 0.95 and 1 . Our focus for this study is on a large resuspension event; thus, we do not expect potential errors in in situ backgrounds to have significant impacts on our findings, and the correction far outweighs the alternative of using only the prestorm background correction. This approach should be used with caution when studying smaller concentrations in shallow water and will likely be more effective in deep ocean deployments with long durations of clear water measurements.

After background correction, we apply a four-point median filter on raw 1-s angular scattering data to remove measurements of spurious large particles. After filtering, angular scattering data were inverted into a volume PSD with a Sequoia Scientific-provided algorithm (Agrawal and Pottsmith 2000). We used the inversion kernel developed empirically for randomly shaped natural particles (Agrawal et al. 2008). All inversions were performed on the full-resolution datasets then linearly interpolated to align with glider science computer time stamps. The inverted solutions result in 36 log-spaced size classes from $1.00-$ to $500-\mu \mathrm{m}$ diameters. We evaluate the impacts our correction method by comparing PSDs using only the predeployment background measurements, and after applying our dynamic in situ corrections. Volume concentrations are presented at three time points, ahead of the resuspension event at 1200 UTC 18 September, during peak sediment resuspension at 1200 UTC 19 September, and after sediment resuspension at 1200 UTC 21 September. Pre-event and postevent time points were bin averaged over $2 \mathrm{~m}$ at $5-\mathrm{m}$ depth, and the storm time point was bin averaged at $19-\mathrm{m}$ 

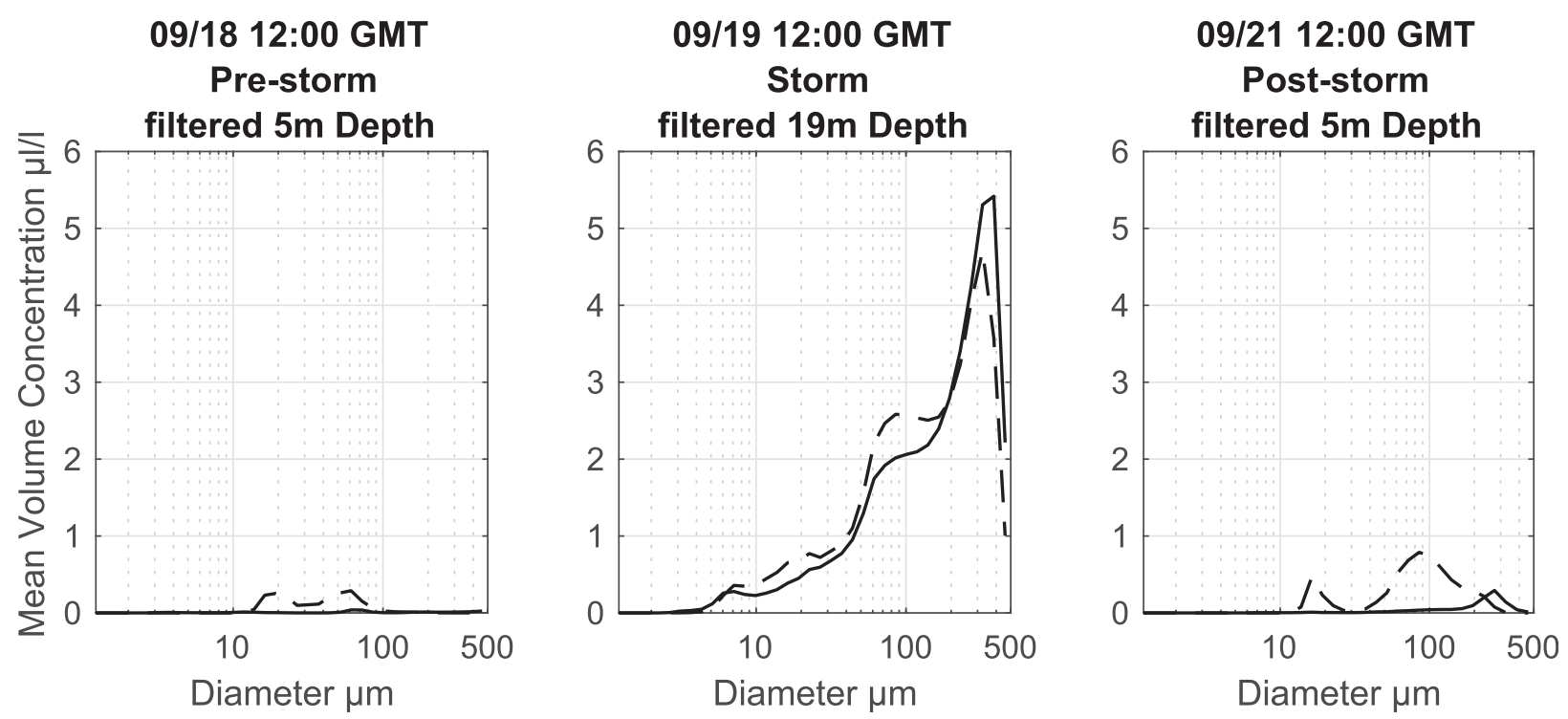

FIG. 6. Two-hourly and 2-m bin center-averaged mean volume concentrations at 5-m depth (left) ahead of and (right) after the storm event as well as (center) near the bottom at 19-m depth during the storm resuspension event.

depth, near the bed. Each bin was calculated as a center average in time over $2 \mathrm{~h}$, containing between 44 and 96 samples each. These time periods and depths were selected in unstratified regions to limit potential schlieren impacts. Dynamic in situ background corrections show a clear removal with two peaks between 10 and $100 \mu \mathrm{m}$ in all three time periods (Fig. 6). This persistent feature was likely due to contamination on the instrument windows during the prestorm background that was subsequently removed, or a scratch or persistent contamination throughout the deployment. Regardless of the correction, it is small relative to the observed resuspension signal shown in the middle time period (Fig. 6b). Future studies should utilize water and bottom sediment sampling at glider deployment and recovery to more clearly assess background corrections, specifically when sampling in time periods and locations with low concentrations. The remainder of this paper uses volume concentrations that have had the dynamic and interpolated in situ corrections applied.

\section{b. Schlieren corrections}

Microscale turbulent shear can lead to changes in index of refraction in proximity to large density gradients (Mikkelsen et al. 2008). This well-known effect, commonly referred to as schlieren, can result in measurement of forward scattering by optical instruments without the presence of suspended particles. In the LISST family of instruments this leads to elevated estimates of beam attenuation and the volume scattering function for the innermost ring detectors, corresponding with large particle sizes. Previous analyses have identified schlieren as contributing to increases in beam attenuation and increase in particle volume for buoyancy frequencies $N$ ranging from 0.02 to $0.05 \mathrm{~s}^{-1}$ (Mikkelsen et al. 2008; Tao et al. 2017) with contamination likely outside these ranges in a variety of other field sites. A study (Styles 2006) using a type-C LISST identified schlieren effects on the nine innermost rings, corresponding to particle sizes greater than $128 \mu \mathrm{m}$. We calculate correlation coefficients of each of the 36 size bins with $N$ during periods where $N$ exceeded $0.02 \mathrm{~s}^{-1}$ to evaluate schlieren impacts on volume concentration estimates. This approach of calculating conditional correlation coefficients has similarities to Tao et al. (2017).

Total volume concentrations are plotted in (Fig. 7a). There are two distinct regions of elevated concentrations, beneath the pycnocline during stratified conditions (0000 UTC 182000 UTC 19 September), and throughout the unstratified time period during peak storm conditions (2000 UTC 190000 UTC 21 September). During the stratified time period, measurements of bb700 only show limited suspended particles $\sim 1-2 \mathrm{~m}$ above bottom (mab) (Fig. 7c), while buoyancy frequencies are elevated throughout the entire bottom layer (Fig. 7b). This suggests that the observed total volume concentrations measured by the LISST in the bottom stratified layer may be contaminated by schlieren effects.

To evaluate particle size ranges that may be affected by schlieren, we compared volume concentrations from each LISST size bin with $N>0.02 \mathrm{~s}^{-1}$ (Fig. 8). During the full storm time period (0000 UTC 18-1800 UTC 21 September) correlation coefficients between volume concentrations and $N>$ $0.02 \mathrm{~s}^{-1}$ (Fig. 8) were elevated between 0.2 and 0.6 for the four innermost rings, while all remaining sizes bins, both for $N<$ $0.02 \mathrm{~s}^{-1}$ and $N>0.02 \mathrm{~s}^{-1}$, were uncorrelated $(<0.1)$. These data indicate that schlieren effects are present during stratified conditions when bb700 values (not expected to be affected by schlieren) are low (Figs. 7b,c) and are not present when the water column becomes unstratified and the main storm-driven sediment resuspension event occurs. Scattering by density fluctuations scale with the Kolmogorov scale, mostly affecting inner rings. Thus, to mitigate the effects of schlieren on total volume concentration estimates, measurements from the four innermost ring detectors (particle diameters $>250 \mu \mathrm{m}$ ) were excluded from raw scattering data and inversion when $N$ was 

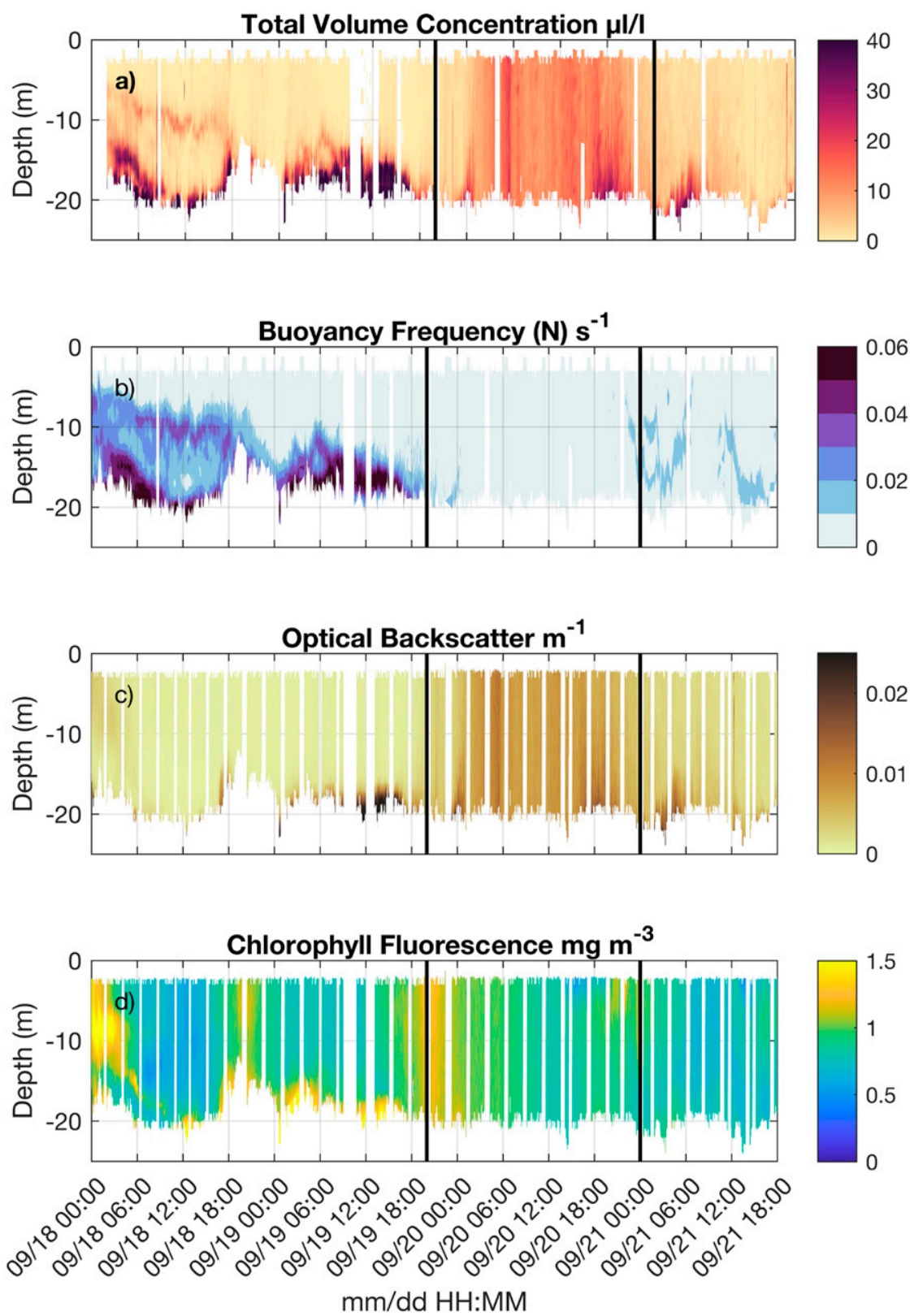

FIG. 7. Glider cross sections of (a) total volume concentration, (b) buoyancy frequencies, (c) optical backscatter, and (d) chlorophyll fluorescence. Vertical black lines represent the primary resuspension event time period.

greater than 0.02 (Fig. 9e) and thus are also not included as contributions to total volume concentrations throughout the remainder of the study (Fig. 9a).

\section{Storm-driven sediment resuspension and transport}

As described in section 2c, RU28 was programmed to station keep near Buoy 44091 and just offshore of the Tuckerton RUMFS meteorological station throughout the duration of an extratropical storm event. The storm event transited northeastward through the mid-Atlantic region typical of an early season nor'easter. Wind speeds (Fig. 3) measured at RUMFS showed an increase from $5 \mathrm{~m} \mathrm{~s}^{-1}$ on 0000 UTC 18 September to a peak near $15 \mathrm{~m} \mathrm{~s}^{-1}$ just after 1200 UTC 19 September. Winds rotated from due east to north throughout the storm event. Peak waves at Buoy 44091 coincided with peak winds, with significant wave heights reaching $4 \mathrm{~m}$. Average wave periods were short, between 6 and $7 \mathrm{~s}$, for the duration of the storm event. Wind and wave conditions gradually reduced to prestorm conditions throughout 20 and into 21 September.

During prestorm conditions at 0000 UTC 18 September the water column was vertically stratified (Fig. 4). The surface 


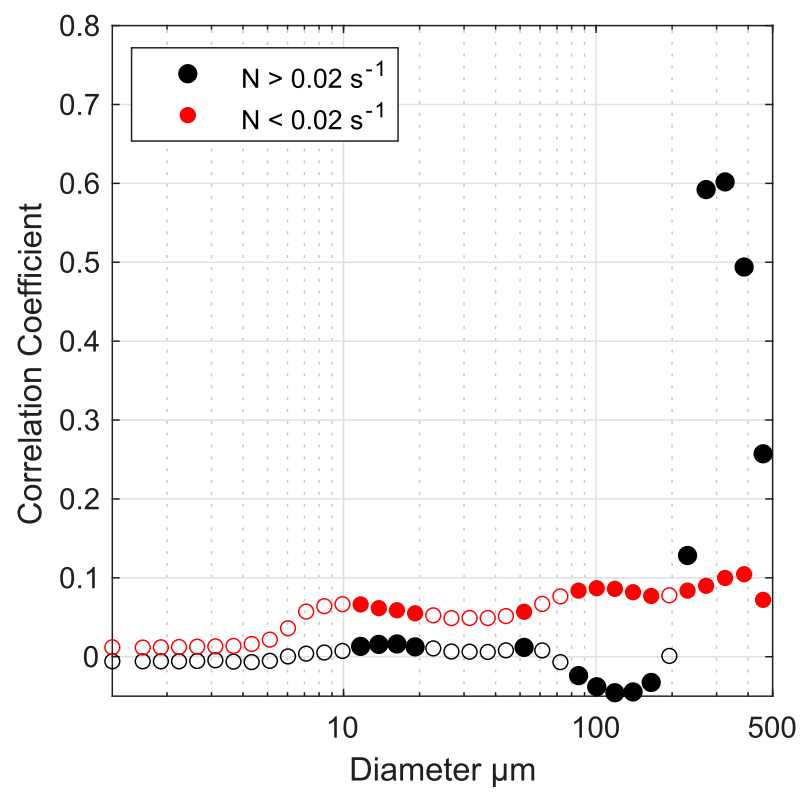

FIG. 8. Correlation coefficients between buoyancy frequency and scattering for each particle diameter measured. Analysis was separated out for values of $N<0.02 \mathrm{~s}^{-1}$ (red) and $N>0.02 \mathrm{~s}^{-1}$ (black). Closed circles are significant with $P>0.05$.

mixed layer depth (SMLD) was calculated following Evans et al. (2018) using a vertical density gradient criteria of $0.1 \mathrm{~kg} \mathrm{~m}^{-3} \mathrm{~m}^{-1}$ to identify the base of the mixed layer. The surface mixed layer initially was found at 5-m depth on 0000 UTC 18 September and steadily fell until it reached the bottom on 1800 UTC 19 September. Above the SMLD temperature, salinity, and density were vertically uniform near $22^{\circ} \mathrm{C}, 30.9 \mathrm{~g} \mathrm{~kg}^{-1}$, and $1021 \mathrm{~kg} \mathrm{~m}^{-3}$, respectively. Below this surface layer the water column was continuously stratified with temperatures decreasing with depth to $19.5^{\circ} \mathrm{C}$, salinities of $31.2 \mathrm{~g} \mathrm{~kg}^{-1}$, and densities of $1022 \mathrm{~kg} \mathrm{~m}^{-3}$. After $1800 \mathrm{UTC}$ 19 September the temperature, salinity, and density were vertically uniform throughout the water column at $21^{\circ} \mathrm{C}$, $31.1 \mathrm{~g} \mathrm{~kg}^{-1}$, and $1021.5 \mathrm{~kg} \mathrm{~m}^{-3}$ during this period. After 0000 UTC 21 September the water column began to restratify following the cessation of storm conditions. The near-bottom stratification ahead of the storm is characteristic of remnant bottom summer cold pool waters, which are seasonally eroded by storm-driven mixing and reductions in surface heat flux during the transition into autumn (Castelao et al. 2008).

With both background corrections applied and effects of schlieren removed we can now use the LISST-Glider data to evaluate storm-driven sediment resuspension and transport. Particle volume concentrations were binned according to phi unit size class ranges for silts (phi $>4$ or grain sizes $<64 \mu \mathrm{m}$; Fig. 9b), very fine sands (phi 4-3 or 64-125 $\mu \mathrm{m}$ Fig. 9c), fine sands (phi 3-2 or 125-250 $\mu \mathrm{m}$; Fig. 9d), and medium sands (phi $2-1$ or $250-500 \mu \mathrm{m}$; Fig. 9e). On 2000 UTC 19 September, following water column destratification, total volume concentrations increased throughout the full water column (Fig. 9a) and remained elevated until 0000 UTC 21 September. Elevated concentrations were seen across silts, very fine, and fine sands, with little contribution from of medium sands to the total concentration. To demonstrate the uniformity of the distribution throughout the water column in more detail we calculate the mean particle size distribution in the surface $(<10-\mathrm{m}$ depth) and bottom $(>10-\mathrm{m}$ depth) during the initial peak resuspension period from 0000 to 1600 UTC 20 September. Distributions were nearly identical (Fig. 10a), suggesting either uniform turbulence throughout the water column, or more likely that turbulent buoyancy forces exceeded gravitational settling forces for the available sediment supply. During the end of the resuspension period between 1600 UTC 20 and 0000 UTC 21 September (Fig. 10b), surface and bottom particle size distributions showed elevated concentrations near the bottom and decreased concentrations in the surface layer for particle sizes $>72 \mu \mathrm{m}$. This indicates that, with weakening storm conditions, gravitational settling forces likely exceeded turbulent buoyancy forces for larger particles, and they began to fall out of suspension.

To evaluate the predicted ratio of turbulence to settling velocities we utilize the standard Rouse profile for resuspended sediment under neutral conditions (Glenn et al. 2008):

$$
C(z)=C_{r}\left(z / z_{r}\right)^{\left[-\gamma w_{f} /\left(\kappa u_{*}\right)\right]},
$$

where $C(z)$ is sediment concentration at depth $z, C_{r}$ is sediment concentration at a reference depth $z_{r}, w_{f}$ is a settling velocity defined below, $u_{*}$ is turbulent shear velocity, and $\gamma$ and $\kappa$ are constants. Von Kármán's $\kappa$ is set 0.4 , while $\gamma$ is set to 0.8 (Glenn and Grant 1987). Equation (1) can be rearranged to solve for the ratio of settling and turbulent shear velocity:

$$
w_{f} / u_{*}=-(\kappa / \gamma)\left\{\ln \left[C(z) / C_{r}\right] / \ln \left(z / z_{r}\right)\right\} .
$$

The right-hand side of the equation can be obtained using the constants above and by taking the slope of a linear fit of the concentration profile in the unstratified region outside the bottom boundary layer. Two hourly-averaged profiles of potential density, total volume concentration, and bb700 are displayed at 3-hourly intervals between 2000 UTC 19 and 1700 UTC 21 September (Fig. 11) in semilog-y (density) and $\log -\log$ (total volume concentration and bb700) space. We fit a line linearly in $\log -\log$ space to values of the total volume concentration and bb700 in the bottom mixed layer, in this case contained to the lower $5 \mathrm{~m}$ of the water column. Profile fits where $r$-squared values were less than 0.3 (0500 and 1400 UTC 20 September) were not included. Settling velocities were estimated from the mean profile particle size at each time point (Fig. 11a) following the method of Soulsby (1997) for irregular grains:

$$
w_{f}=\frac{\nu}{d}\left[\left(10.36^{2}+1.049 D_{*}^{3}\right)^{1 / 2}-10.36\right],
$$

where $\nu$ is the kinematic viscosity of water, $d$ is the grain diameter, and $D_{*}$ is a dimensionless grain size:

$$
D_{*}=\left[\frac{g(s-1)}{\nu^{2}}\right]^{1 / 3} d,
$$



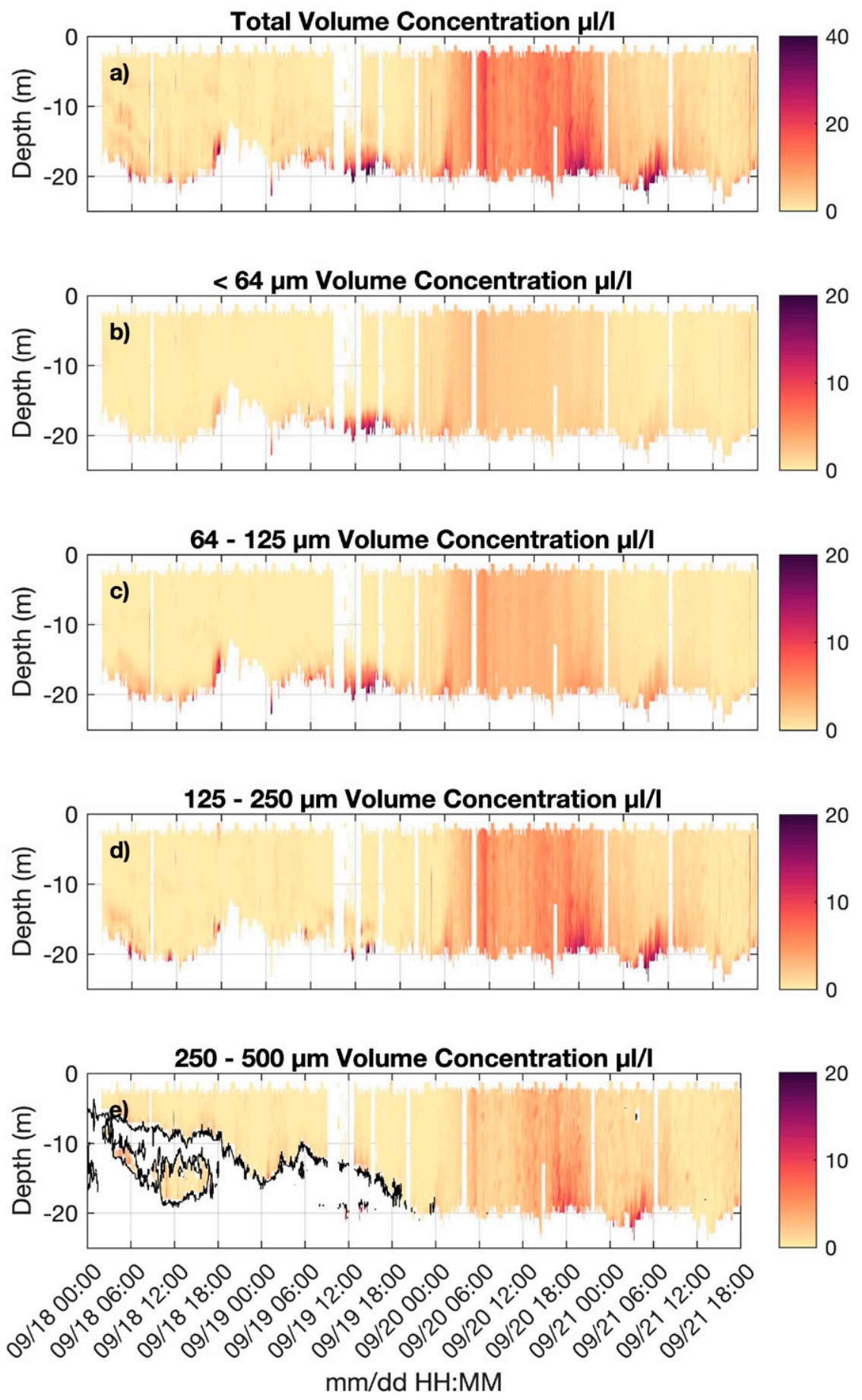

FIG. 9. Glider cross sections of (a) corrected total volume concentration and volume concentration (b) $<64 \mu \mathrm{m}$, (c) between 64 and $125 \mu \mathrm{m}$, (d) between 125 and $250 \mu \mathrm{m}$, and (e) between 250 and $500 \mu \mathrm{m}$. The black contour in (e) denotes the region where $N>0.02 \mathrm{~s}^{-1}$ and data were removed.

with $g$ being the acceleration due to gravity and $s$ the ratio of densities of sand and water. Solving $w_{f}$ from the LISST mean grain size measurements and an assumed density of $2650 \mathrm{~kg} \mathrm{~m}^{-3}$ for the predominantly sandy site, leaves $u_{*}$ as the only remaining unknown. We then solve Eq. (2) using slopes from both total volume concentration and bb700 fits for two estimates of $u_{*}$. Estimates of settling velocities for the fixed particle sizes of $150 \mu \mathrm{m}\left(w_{f 150}\right.$, the maximum observed mean particle size) and 


\section{Mean Particle Size Distribution}
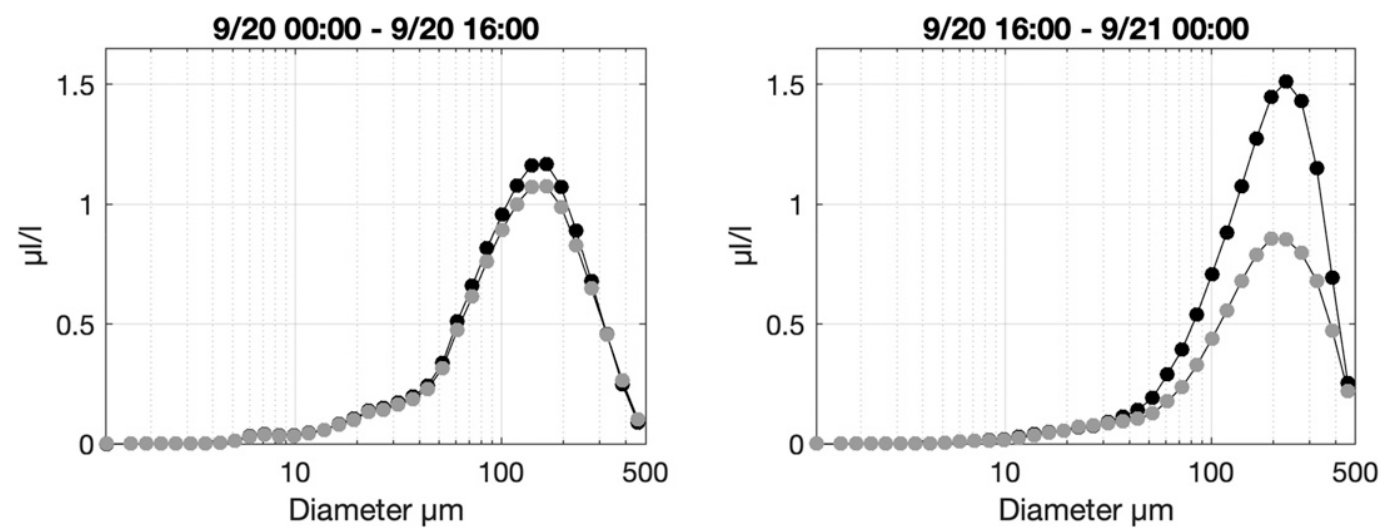

FIG. 10. Mean volume concentrations in the upper $10 \mathrm{~m}$ (gray) and below $10 \mathrm{~m}$ (black), showing (left) distributions during the initial resuspension phase and (right) distributions during the beginning of the settling phase.

$500 \mu \mathrm{m}\left(w_{f 500}\right.$, the maximum size range sampled by the LISSTGlider) are plotted for reference on Fig. 11b.

There is good agreement between $u_{*}$ estimates from both the LISST and ECO Triplet sensors for the majority of the storm forcing period with $u_{*}$ reaching values of nearly $0.5 \mathrm{~m} \mathrm{~s}^{-1}$ at peak storm forcing. The good agreement between the slopes and $u_{*}$ from the LISST and ECO Triplet suggest that both sensors have similar sensitivity to particle size for the unimodal sands sampled at this study site. This approach should be used with caution at other locations with different particle characteristics. At the first two time points (2000 and 2300 UTC 19 September), $u_{*}$ was low below both $w_{f 150}$ and $w_{f 500}$. Profiles show a limited bottom mixed layer extending up to 5 mab. Below this depth, slopes were shallow and the associated particle sizes were small, close to $50 \mu \mathrm{m}$. Between 0200 and 1400 UTC 20 September the bottom mixed layer extended throughout the full water column. Slopes of the total volume concentrations were steep and nearly vertical throughout this time period, corresponding to peak values of $u_{*}$, representing a significant increase in turbulence throughout the water column. As storm conditions are reduced after 1700 UTC 20 September the $u_{*}$ values fall and profiles shallow consistent with sediment falling out of suspension. As mentioned above, these estimates of $u_{*}$ and interpretation of the profiles are based on the solution for Eq. (1) under neutral conditions. As described in Glenn and Grant (1987), this assumption holds when the stability parameter $z / L$ (with $z$ being the depth and $L$ the MoninObukhov length), multiplied by the constant $\beta \sim 4.7$ is $\ll$ than $\gamma$. We calculate $\beta(z / L)$ at the top and bottom of the fit profiles at 1 and $5 \mathrm{~m}$ following Eq. (43) presented in Glenn and Grant (1987) to evaluate the range of the potential stability parameters above the wave bottom boundary layer. The equation is adapted here where we use only the mean particle size estimate of fall velocity and the $u_{*}$ estimated from the LISST-Glider only:

$$
\frac{z}{L}=\frac{\kappa z}{u_{*}^{3}} g(s-1) w_{f} C(z)
$$

Results are plotted in Fig. 11c and show that for all but four time points $\beta(z / L)$ at both depths is much less than $\gamma$, indicating that the neutral solutions are valid. Values of $\beta(z / L)$ were close to, or exceeded $\gamma$ at four time points, 2000 UTC 19 and 0200 , 1400, and 1700 UTC 21 September. All time points where assumptions of neutral conditions were invalid fell outside the main resuspension event, with the measurement 0200 UTC 21 September being associated with a peak in a secondary event (Fig. 9) seen across all size classes. This secondary event is an ideal candidate for future investigation of suspended sediment stratification, which is described in detail in Glenn and Grant (1987) but has not been previously observed in the field.

The above results and estimated sediment transport from the LISST-Glider are summarized in Fig. 12. Volume concentrations, plotted at three heights $(5,7$, and $10 \mathrm{mab}$, Fig. 12a) show initially low concentrations despite high bottom orbital velocities (Fig. 12e), and high depth-averaged velocities (Fig. 12d). The elevated buoyancy frequencies (Fig. 12c) highlight that stratification likely restricts the full resuspension of sediment throughout the water column. As buoyancy frequency drops when the water column becomes unstratified, volume concentrations increase at all three depths. As bottom orbital velocities fall on 1400 UTC 20 September the concentrations at the three depths begin to separate, with elevated concentrations near the bed and reduced concentrations near the surface consistent with what was shown in Fig. 11 with sediment falling out of suspension. While all values fall by 0000 UTC 21 September, there is a brief increasing period for the near bed measurements that is timed with our findings that $\beta(z / L)$ exceeded $\gamma$, as described above. There are two main peaks in suspended load transport at 0300 UTC 20 September and approximately $12 \mathrm{~h}$ later at 1500 UTC 20 September. The peaks align with peak depthaveraged velocity and are consistent with the $\mathrm{M}_{2}$ tidal period of $12.42 \mathrm{~h}$, the dominant tidal constituent within the MAB. Tidal modulation of sediment transport is similar to what was observed in Glenn et al. (2008), with tidal forcing increasing resuspension and transport even after peak storm conditions. We do not expect these currents to be driven by inertial oscillations as the peaks appear with a frequency shorter than 
Sigma $\mathrm{kg} \mathrm{m}^{-3}$
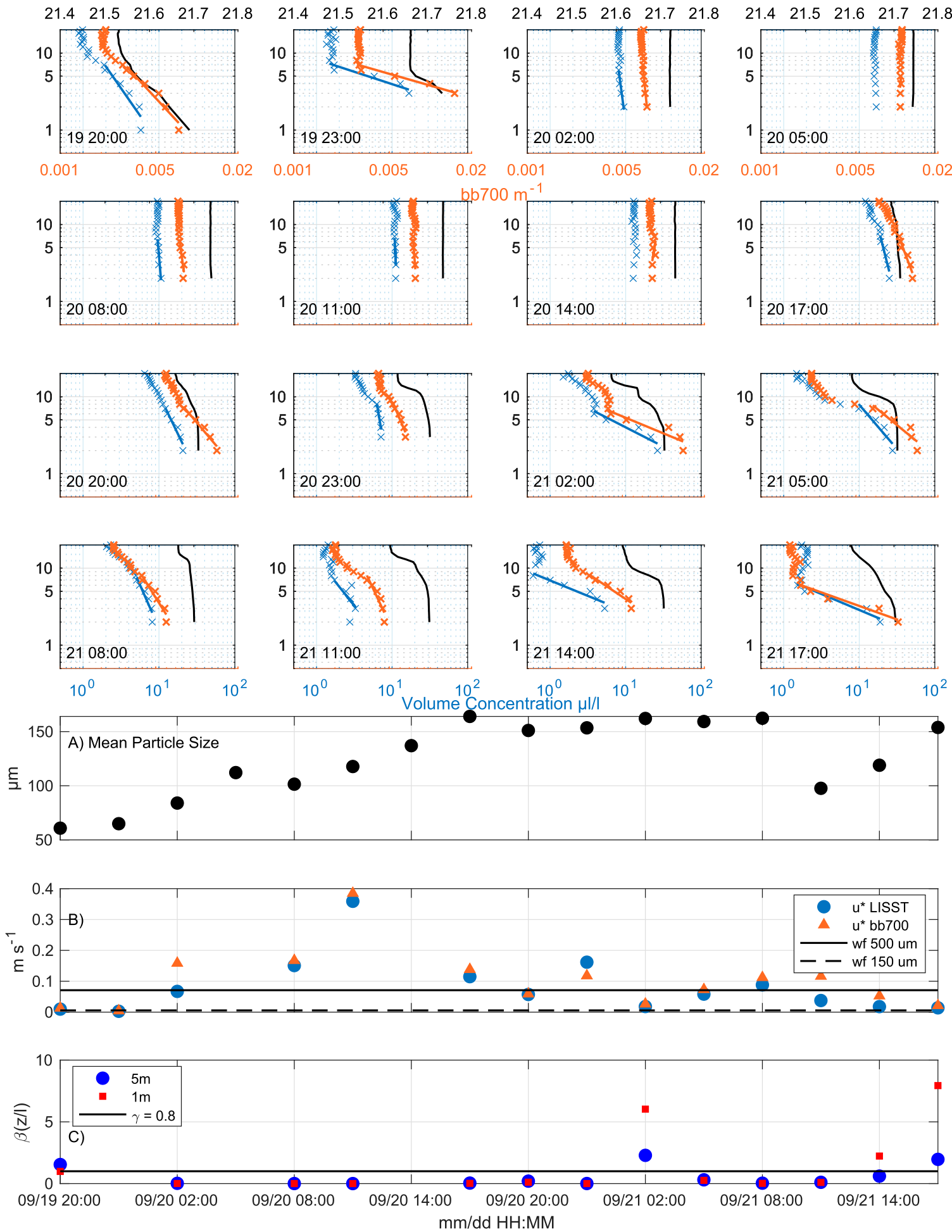

FIG. 11. (top) Hourly-averaged profiles at 3-h intervals of density in sigma units (black), bb700 (orange), and volume concentration (blue). Blue lines are linear regressions of volume concentration in the bottom mixed layer, excluding profiles where $r$-squared values are $<0.3$. (a) The mean particle sizes averaged over the lower $5 \mathrm{~m}$, (b) estimates of $u_{*}$ derived from the linear fits to LISST total volume concentration profiles (blue) and bb700 (orange), with horizontal lines indicating fall velocities for particles of 500 (solid black) and 150 (dashed black line) $\mu \mathrm{m}$, and (c) estimates of $\beta(z / L)$ at the 5-m depth (blue) and 1-m depth (red) with constant $\gamma$ (horizontal black line). 

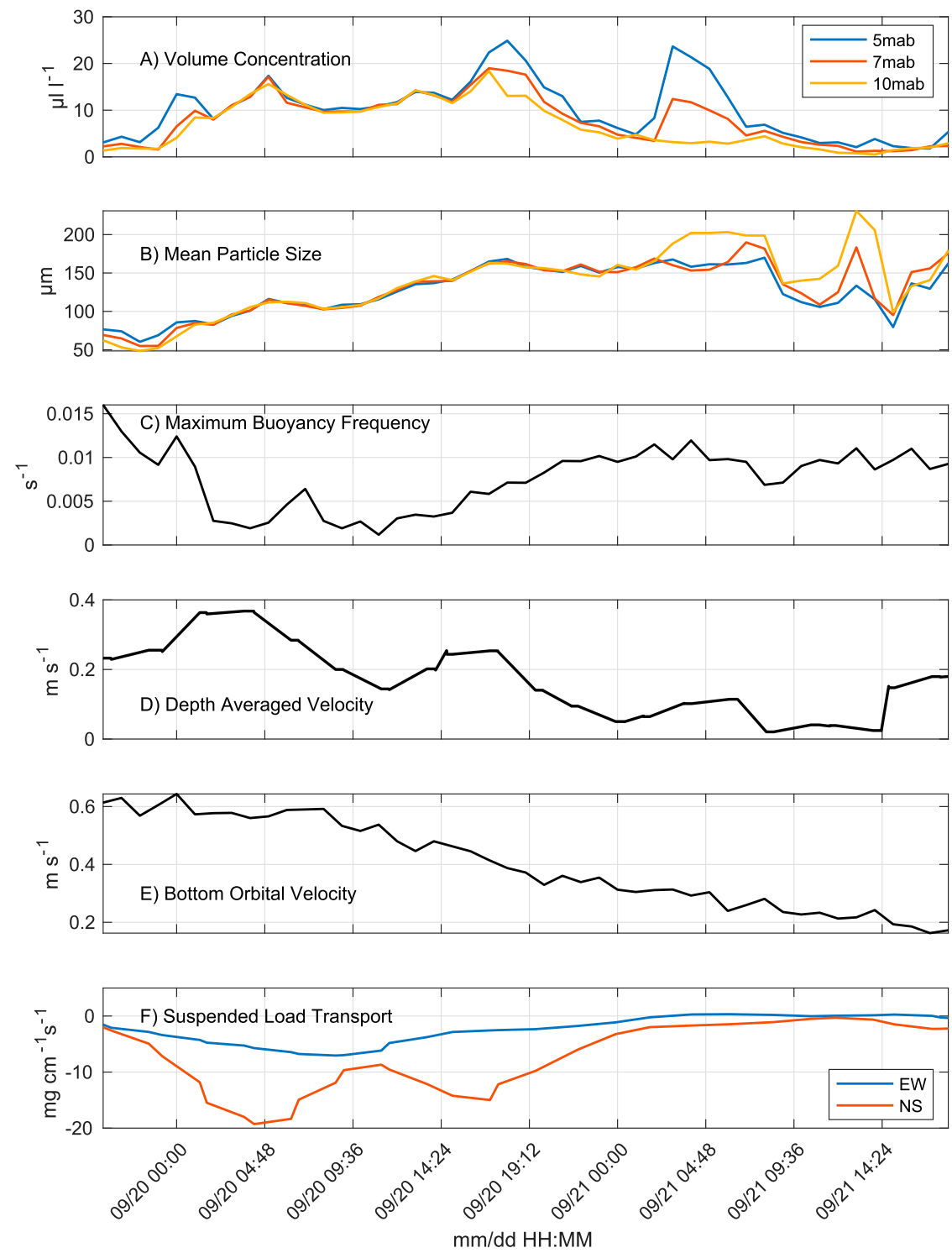

FIG. 12. Time series of (a) volume concentration and (b) mean particle size at depths of 5 (blue), 7 (red), and 10 (yellow) mab, (c) maximum buoyancy frequency, (d) depth-averaged velocity, (e) bottom orbital velocities at 44091, and (f) LISST-Glider estimated suspended load transport.

the local inertial period $(\sim 18 \mathrm{~h})$. The total depth- and timeintegrated suspended sediment load estimated for this particular event is $311 \mathrm{mg} \mathrm{cm}^{-1}$, which is within the range of what has previously been estimated on the inner MAB shelf (Styles and Glenn 2005).

\section{Discussion and conclusions}

This study presents the first measurements from a Sequoia Scientific LISST integrated into an autonomous underwater glider and includes initial procedures for quality assurance and control on board this unique platform. This included implementation and demonstration of in situ background corrections similar to those for shipboard measurements (Barone et al. 2015). This combination of the LISST, along with additional optical sensors, on the glider platform allowed for a fuller description of the optical properties and sediment environment than previously deployed optical instruments on profiling gliders (Glenn et al. 2008; Miles et al. 2013; Many et al. 2016; Bourrin et al. 2015). This capability represents a significant advance in our ability to obtain detailed high-quality optical measurements from a single profiling sensor platform that was previously only possible from ship-based or moored platforms.

As an example of these capabilities, we characterized sediment resuspension and transport during a coastal storm on the $\mathrm{MAB}$. A region regularly impacted by storm events and with a 
long history of sediment resuspension and transport studies (Styles and Glenn 2005; Agrawal 2005; Boss et al. 2004; Traykovski et al. 1999; Gargett et al. 2004). In addition to enabling in situ monitoring of sediment characteristics these data enabled us to infer bottom turbulent shear velocities based on the slope of the concentration and bb700 profiles combined with fall velocities from the mean particle size. These measurements and analyses will be particularly useful in calibrating sediment resuspension and transport models and their associated parameterizations, such as the Community Sediment Transport Model coupled to ROMS (Warner et al. 2010; Wu et al. 2011), which have been regularly used to study stormdriven sediment resuspension and transport (Warner et al. 2008; Ralston et al. 2013; Miles et al. 2015; Yang et al. 2015; Warner et al. 2017).

Despite these successes, limitations remain, in particular with regard to our ability to make regular background corrections with equivalent certainty as those used in shipboard or laboratory studies. Methods utilizing pre- and postdeployment background measurements and in situ data during optically clear conditions remain viable methods for determining vicarious background corrections and mitigating the effects of fouling over long-term deployments. Additional use of paired optical backscatter and fluorescence measurements are strongly encouraged to help interpret the effects of schlieren as well as to monitor potential biofouling, especially if LISST-Gliders are deployed for the full range of a glider's duration, from a month up to a year.

This study represents the first of these paired technologies, narrowly focused on storm-driven sediment resuspension. However, there are significant opportunities to expand these analyses with other paired bio-optical measurements to quantify additional particle characteristics, potentially including particle composition, shape, and color. In addition to other bio-optical sensors, coincident measurements with physical sensors such as glider-integrated acoustic Doppler current profilers or turbulent microstructure can enable better quantification of turbulent production and near bottom turbulent shear for resuspension studies. Even more promising is the use of LISST-Gliders as a distributed network to calibrate and validate satellite remote sensing over a broad array of conditions and environments for sustained periods. These advances will only be possible with continued collaboration and development among academic institutions, private companies, and a diverse set of federal and state funding agencies and laboratories.

Acknowledgments. This work was supported by the Office of Naval Research (ONR) Award N00014-16-1-2553 as well as a leveraged glider deployment supported by the New Jersey Department of Environmental Protection. The authors acknowledge the dedicated work of the engineers at both Sequoia Scientific, Inc., and Teledyne Webb Research in performing the sensor integration, as well as technicians at the Rutgers University Center for Ocean Observing Leadership. The Tuckerton Met Tower is maintained by Weatherflow, Inc. (https://weatherflow.com/), which includes biannual repair and maintenance. We give thanks to Oscar Schofield for providing commentary on early versions of the analysis presented herein. We also thank reviewers Emmanuel Boss, an anonymous reviewer, and the journal editor for their constructive and thoughtful comments and suggestions.

Data availability statement. Glider delayed-mode data, including onboard processed LISST data, are publicly available through a NOAA designed ERDDAP server hosted at the Rutgers University Center for Ocean Observing Leadership (http://slocum-data.marine.rutgers.edu/erddap/tabledap/ru2820170915T1416-profile-sci-delayed.html). Real-time data from the deployment can be found within the NOAA Integrated Ocean Observing System (IOOS) glider Data Assembly Center (DAC; https://gliders.ioos.us/). Raw binary LISST data files were downloaded postdeployment and can be found via the open data repository Zenodo (https://doi.org/ 10.5281/zenodo.4325447).

\section{REFERENCES}

Agrawal, Y. C., 2005: The optical volume scattering function: Temporal and vertical variability in the water column off the New Jersey coast. Limnol. Oceanogr., 50, 1787-1794, https:// doi.org/10.4319/lo.2005.50.6.1787.

_ and H. C. Pottsmith, 2000: Instruments for particle size and settling velocity observations in sediment transport. Mar. Geol., 168, 89-114, https://doi.org/10.1016/S0025-3227(00) 00044-X.

—_, and P. Traykovski, 2001: Particles in the bottom boundary layer: Concentration and size dynamics through events. J. Geophys. Res., 106, 9533-9542, https://doi.org/10.1029/ 2000JC900160.

- and O. A. Mikkelsen, 2009: Shaped focal plane detectors for particle concentration and mean size observations. Opt. Express, 17, 23 066-23 077, https://doi.org/10.1364/OE.17.023066.

—- A. Whitmire, O. A. Mikkelsen, and H. C. Pottsmith, 2008: Light scattering by random shaped particles and consequences on measuring suspended sediments by laser diffraction. J. Geophys. Res., 113, C04023, https://doi.org/ 10.1029/2007JC004403.

Ahn, J. H., S. B. Grant, C. Q. Surbeck, P. M. Digiacomo, N. P. Nezlin, and S. Jiang, 2005: Coastal water quality impact of stormwater runoff from an urban watershed in Southern California. Environ. Sci. Technol., 39, 5940-5953, https:// doi.org/10.1021/es0501464.

Barone, B., R. R. Bidigare, M. J. Church, D. M. Karl, R. M. Letelier, and A. E. White, 2015: Particle distributions and dynamics in the euphotic zone of the North Pacific Subtropical Gyre.J. Geophys. Res. Oceans, 120, 3229-3247, https://doi.org/ 10.1002/2015JC010774.

Bejarano, A. C., E. Levine, and A. J. Mearns, 2013: Effectiveness and potential ecological effects of offshore surface dispersant use during the Deepwater Horizon oil spill: A retrospective analysis of monitoring data. Environ. Monit. Assess., 185, 10 281-10 295, https://doi.org/10.1007/s10661-013-3332-y.

Boss, E., W. S. Pegau, M. Lee, M. Twardowski, E. Shybanov, G. Korotaev, and F. Baratange, 2004: Particulate backscattering ratio at LEO 15 and its use to study particle composition and distribution. J. Geophys. Res., 109, C01014, https://doi.org/ 10.1029/2002JC001514.

— , N. Haëntjens, T. K. Westberry, L. Karp-Boss, and W. H. Slade, 2018a: Validation of the particle size distribution 
obtained with the Laser in-Situ Scattering and Transmission (LISST) meter in flow-through mode. Opt. Express, 26, 11 125-11 136, https://doi.org/10.1364/OE.26.011125.

— , C. R. Sherwood, P. Hill, and T. Milligan, 2018b: Advantages and limitations to the use of optical measurements to study sediment properties. Appl. Sci., 8, 2692, https://doi.org/ 10.3390/app8122692.

Bourrin, F., and Coauthors, 2015: Glider monitoring of shelf suspended particle dynamics and transport during storm and flooding conditions. Cont. Shelf Res., 109, 135-149, https:// doi.org/10.1016/j.csr.2015.08.031.

Bunt, J. C., P. Larcombe, and C. F. Jago, 1999: Quantifying the response of optical backscatter devices and transmissometers to variations in suspended particulate matter. Cont. Shelf Res., 19, 1199-1220, https://doi.org/10.1016/S0278-4343(99)00018-7.

Castelao, R., S. Glenn, O. Schofield, R. Chant, J. Wilkin, and J. Kohut, 2008: Seasonal evolution of hydrographic fields in the central Middle Atlantic Bight from glider observations. Geophys. Res. Lett., 35, L03617, https://doi.org/10.1029/ 2007 GL032335.

Chang, G. C., T. D. Dickey, and A. J. Williams, 2001: Sediment resuspension over a continental shelf during Hurricanes Edouard and Hortense. J. Geophys. Res., 106, 9517-9531, https://doi.org/10.1029/2000JC900032.

Curran, K. J., P. S. Hill, T. G. Milligan, O. A. Mikkelsen, B. A. Law, X. Durrieu de Madron, and F. Bourrin, 2007: Settling velocity, effective density, and mass composition of suspended sediment in a coastal bottom boundary layer, Gulf of Lions, France. Cont. Shelf Res., 27, 1408-1421, https://doi.org/ 10.1016/j.csr.2007.01.014.

Dickey, T. D., G. C. Chang, Y. C. Agrawal, A. J. Williams, and P. S. Hill, 1998: Sediment resuspension in the wakes of Hurricanes Edouard and Hortense. Geophys. Res. Lett., 25, 3533-3536, https://doi.org/10.1029/98GL02635.

Evans, D. G., and Coauthors, 2018: Annual cycle of turbulent dissipation estimated from Seagliders. Geophys. Res. Lett., $\mathbf{4 5}$, 10 560-10 569, https://doi.org/10.1029/2018GL079966.

Gargett, A., J. Wells, A. E. Tejada-Martínez, and C. E. Grosch, 2004: Langmuir supercells: A mechanism for sediment resuspension and transport in shallow seas. Science, 306, 19251928, https://doi.org/10.1126/science.1100849.

Glenn, S. M., and W. D. Grant, 1987: A suspended sediment stratification correction for combined wave and current flows. J. Geophys. Res., 92, 8244-8264, https://doi.org/ 10.1029/JC092iC08p08244.

—, C. Jones, M. Twardowski, L. Bowers, J. Kerfoot, J. Kohut, D. Webb, and O. Schofield, 2008: Glider observations of sediment resuspension in a Middle Atlantic Bight fall transition storm. Limnol. Oceanogr., 53, 2180-2196, https://doi.org/ 10.4319/lo.2008.53.5_part_2.2180.

— with tropical cyclones. Nat. Commun., 7, 10887, https://doi.org/ 10.1038/ncomms10887.

Goff, J., C. J. Jenkins, and S. Jeffress Williams, 2008: Seabed mapping and characterization of sediment variability using the usSEABED data base. Cont. Shelf Res., 28, 614-633, https:// doi.org/10.1016/j.csr.2007.11.011.

Harris, C. K., B. Butman, and P. Traykovski, 2003: Winter-time circulation and sediment transport in the Hudson Shelf Valley. Cont. Shelf Res., 23, 801-820, https://doi.org/10.1016/S02784343(03)00025-6.

Holdaway, G. P., P. D. Thorne, D. Flatt, S. E. Jones, and D. Prandle, 1999: Comparison between ADCP and transmissometer measurements of suspended sediment concentration. Cont. Shelf Res., 19, 421-441, https://doi.org/10.1016/S0278-4343(98) 00097-1.

Houghton, R. W., R. Schlitz, R. C. Beardsley, B. Butman, and J. L. Chamberlin, 1982: The Middle Atlantic Bight cold pool: Evolution of the temperature structure during summer 1979. J. Phys. Oceanogr., 12, 1019-1029, https://doi.org/10.1175/ 1520-0485(1982)012<1019:TMABCP > 2.0.CO;2.

Karp-Boss, L., L. Azavedo, and E. Boss, 2007: LISST-100 measurements of phytoplankton size distribution: Evaluation of the effects of cell shape. Limnol. Oceanogr. Methods, 5, 396406, https://doi.org/10.4319/lom.2007.5.396.

Keen, T. R., and S. M. Glenn, 1995: A coupled hydrodynamicbottom boundary layer model of storm and tidal flow in the Middle Atlantic Bight of North America. J. Phys. Oceanogr., 25, 391-406, https://doi.org/10.1175/1520-0485(1995)025<0391: ACHBLM $>2.0 . \mathrm{CO} ; 2$.

Kohut, J., C. Haldeman, and J. Kerfoot, 2014: Monitoring dissolved oxygen in New Jersey coastal waters using autonomous gliders. EPA Rep. EPA/600/R-13, 180 pp.

—, K. Bernard, W. Fraser, M. J. M. J. Oliver, H. Statscewich, P. Winsor, and T. Miles, 2015: Studying the impacts of local oceanographic processes on Adélie penguin foraging ecology. Mar. Technol. Soc. J., 48, 25-34, https://doi.org/10.4031/MTSJ.48.5.10.

Lentz, S. J., 2017: Seasonal warming of the Middle Atlantic Bight cold pool. J. Geophys. Res. Oceans, 122, 941-954, https:// doi.org/10.1002/2016JC012201.

Lynch, J. F., J. D. Irish, C. R. Sherwood, and Y. C. Agrawal, 1994: Determining suspended sediment particle size information from acoustical and optical backscatter measurements. Cont. Shelf Res., 14, 1139-1165, https://doi.org/10.1016/ 0278-4343(94)90032-9.

— T. F. Gross, C. R. Sherwood, J. D. Irish, and B. H. Brumley, 1997: Acoustical and optical backscatter measurements of sediment transport in the 1988-1989 STRESS experiment. Cont. Shelf Res., 17, 337-366, https://doi.org/10.1016/S0278-4343(96)00041-6.

Manov, D. V., G. C. Chang, and T. D. Dickey, 2004: Methods for reducing biofouling of moored optical sensors. J. Atmos. Oceanic Technol., 21, 958-968, https://doi.org/10.1175/15200426(2004)021<0958:MFRBOM>2.0.CO;2.

Many, G., and Coauthors, 2016: Particle assemblage characterization in the Rhone River ROFI. J. Mar. Syst., 157, 39-51, https://doi.org/10.1016/j.jmarsys.2015.12.010.

Mikkelsen, O. A., and M. Pejrup, 2001: The use of a LISST-100 laser particle sizer for in-situ estimates of floc size, density and settling velocity. Geo-Mar. Lett., 20, 187-195, https://doi.org/ 10.1007/s003670100064.

—, T. G. Milligan, P. S. Hill, R. J. Chant, C. F. Jago, S. E. Jones, V. Krivtsov, and G. Mitchelson-Jacob, 2008: The influence of schlieren on in situ optical measurements used for particle characterization. Limnol. Oceanogr. Methods, 6, 133-143, https://doi.org/10.4319/lom.2008.6.133.

Miles, T., S. Glenn, and O. Schofield, 2013: Temporal and spatial variability in fall storm induced sediment resuspension on the Mid-Atlantic Bight. Cont. Shelf Res., 63, S36-S49, https:// doi.org/10.1016/j.csr.2012.08.006.

— G. Geroka, J. Kohut, O. Schofield, and S. Glenn, 2015: Glider observations and modeling of sediment transport in Hurricane Sandy. J. Geophys. Res. Oceans, 120, 1771-1791, https:// doi.org/10.1002/2014JC010474.

- — , and S. Glenn, 2017: Coastal ocean circulation during Hurricane Sandy. J. Geophys. Res. Oceans, 122, 7095-7114, https://doi.org/10.1002/2017JC013031. 
Ralston, D. K., J. C. Warner, W. R. Geyer, and G. R. Wall, 2013: Sediment transport due to extreme events: The Hudson River estuary after Tropical Storms Irene and Lee. Geophys. Res. Lett., 40, 5451-5455, https://doi.org/10.1002/2013GL057906.

Schofield, O., C. Jones, J. Kohut, U. Kremer, T. Miles, G. Saba, D. Webb, and S. Glenn, 2015: Developing coordinated communities of autonomous gliders for sampling coastal ecosystems. Mar. Technol. Soc. J., 49, 9-16, https://doi.org/10.4031/ MTSJ.49.3.16.

— J. Kohut, U. Kremer, T. Miles, G. Saba, S. Glenn, C. Jones, and D. Webb, 2016: Gliders as maturing technology: Using gliderpalooza as means to develop an integrated glider community. Oceans 2015, Washington, DC, IEEE, https://doi.org/ 10.23919/OCEANS.2015.7404588.

Slade, W., E. Boss, and C. Russo, 2011: Effects of particle aggregation and disaggregation on their inherent optical properties. Opt. Express, 19, 7945, https://doi.org/10.1364/ OE.19.007945.

Soulsby, R. L., 1997: Dynamics of Marine Sands. Thomas Telford, $249 \mathrm{pp}$.

Styles, R., 2006: Laboratory evaluation of the LISST in a stratified fluid. Mar. Geol., 227, 151-162, https://doi.org/ 10.1016/j.margeo.2005.11.011.

, and S. M. Glenn, 2002: Modeling bottom roughness in the presence of wave-generated ripples. J. Geophys. Res., 107, 3110, https://doi.org/10.1029/2001JC000864. , and - , 2005: Long-term sediment mobilization at a sandy inner shelf. J. Geophys. Res., 110, C04S90, https://doi.org/ 10.1029/2003JC002175.

Tao, J., P. S. Hill, E. S. Boss, and T. G. Milligan, 2017: Evaluation of optical proxies for suspended particulate mass in stratified waters. J. Atmos. Oceanic Technol., 34, 2203-2212, https:// doi.org/10.1175/JTECH-D-17-0042.1.

Thorne, P. D., C. E. Vincent, P. J. Hardcastle, S. Rehman, and N. Pearson, 1991: Measuring suspended sediment concentrations using acoustic backscatter devices. Mar. Geol., 98, 7-16, https://doi.org/10.1016/0025-3227(91)90031-X.

, Y. C. Agrawal, and D. A. Cacchione, 2007: A comparison of near-bed acoustic backscatter and laser diffraction measurements of suspended sediments. IEEE J. Oceanic Eng., 32, 225235, https://doi.org/10.1109/JOE.2007.890978.
Traykovski, P., A. E. Hay, J. D. Irish, and J. F. Lynch, 1999: Geometry, migration, and evolution of wave orbital ripples at LEO-15. J. Geophys. Res. Oceans, 104, 1505-1524, https:// doi.org/10.1029/1998JC900026.

Trowbridge, J. H., and A. R. M. Nowell, 1994: An introduction to the Sediment Transport Events on Shelves and Slopes (STRESS) program. Cont. Shelf Res., 14, 1057-1061, https:// doi.org/10.1016/0278-4343(94)90028-0.

Wang, Y. P., G. Voulgaris, Y. Li, Y. Yang, J. Gao, J. Chen, and S. Gao, 2013: Sediment resuspension, flocculation, and settling in a macrotidal estuary. J. Geophys. Res. Oceans, 118, 55915608, https://doi.org/10.1002/jgrc.20340.

Warner, J. C., B. Butman, and P. Dalyander, 2008: Storm-driven sediment transport in Massachusetts Bay. Cont. Shelf Res., 28, 257-282, https://doi.org/10.1016/j.csr.2007.08.008.

—, B. Armstrong, R. He, and J. B. Zambon, 2010: Development of a Coupled Ocean-Atmosphere-Wave-Sediment Transport (COAWST) modeling system. Ocean Modell., 35, 230-244, https://doi.org/10.1016/j.ocemod.2010.07.010.

—, W. C. Schwab, J. H. List, I. Safak, M. Liste, and W. Baldwin, 2017: Inner-shelf ocean dynamics and seafloor morphologic changes during Hurricane Sandy. Cont. Shelf Res., 138, 1-18, https://doi.org/10.1016/j.csr.2017.02.003.

Wiberg, P. L., and C. R. Sherwood, 2008: Calculating wavegenerated bottom orbital velocities from surface-wave parameters. Comput. Geosci., 34, 1243-1262, https://doi.org/ 10.1016/j.cageo.2008.02.010.

Wu, L., C. Chen, P. Guo, M. Shi, J. Qi, and J. Ge, 2011: A FVCOM-based unstructured grid wave, current, sediment transport model, I. Model description and validation. J. Ocean Univ. China, 10, 1-8, https://doi.org/10.1007/ s11802-011-1788-3.

Yang, X., Q. Zhang, J. Zhang, F. Tan, Y. Wu, N. Zhang, H. Yang, and Q. Pang, 2015: An integrated model for three-dimensional cohesive sediment transport in storm event and its application on Lianyungang Harbor, China. Ocean Dyn., 65, 395-417, https://doi.org/10.1007/s10236-014-0806-6.

Yuan, Y., H. Wei, L. Zhao, and W. Jiang, 2008: Observations of sediment resuspension and settling off the mouth of Jiaozhou Bay, Yellow Sea. Cont. Shelf Res., 28, 2630-2643, https:// doi.org/10.1016/j.csr.2008.08.005. 